\title{
THE CONTRIBUTION OF VEGETATION TO THE SHALLOW SLOPES STABILITY
}

\author{
P.P. Capilleri ${ }^{1}$, S. Stacul ${ }^{2}$ D. Lo Presti ${ }^{3}$ \\ ${ }^{1}$ Department of Civil and Industrial Engineering (DICI), Università di Pisa \\ Largo Lucio Lazzarino 1, 56122, Pisa (Italy)-piera.capilleri@unipi.it \\ ${ }^{2}$ Department of Civil and Industrial Engineering (DICI), Università di Pisa \\ Largo Lucio Lazzarino 1, 56122, Pisa (Italy)-stefano.stacul@for.unipi.it \\ ${ }^{3}$ Department of Civil and Industrial Engineering (DICI), Università di Pisa \\ Largo Lucio Lazzarino 1, 56122, Pisa (Italy)-diego.lopresti@unipi.it
}

Key Words: suction, direct shear test, direct shear test large box, water content, friction angle, cohesion.

\begin{abstract}
Geometry is one of the main factors controlling the overall stability of levees, in addition to their hydraulic and mechanical characteristics, while in turn, their material strength strongly depends on their degree of saturation. Given that levees are usually partially saturated (Lo Presti et al., 2020) and that this partial saturation greatly contributes to their stability, any technique aimed at maintaining the levee in this condition is extremely useful. Protection of the levee sides by means of geogrids and biomats reduces the amount of infiltration by water, helps water adsorption by grass vegetation and contributes to mechanical strength thanks to the root apparatus of the grass cover.

Vegetation is a good system for controlling slope erosion and instability. It can reduce the meteoric water that infiltrates into the soil and consequently the pore pressure. On the other hand, the root systems not only keep the soil partially saturated but also increase the soil shear strength with their mechanical contribution.

The mechanical parameters of the root-soil system are important to evaluate the increase in soil shear strength due to the roots. Mechanically, roots contribute to the stabilization/reinforcement of soil by means of an additional apparent cohesion. It is believed that this apparent cohesion originates mainly from the root tensile strength, as well as capillary forces in partially saturated soils.

In terms of root cohesion, an evaluation of this reinforcement can be obtained by means of direct shear tests. The authors set up a systematic experimental activity using a large direct shear box (Vannucci et al. 2019) with the purpose of considering the dual effect of suction and the soil tensile strength. A series of direct shear tests (large and standard shear box) were carried out.
\end{abstract}

This paper presents the results of an experimental laboratory investigation on samples of rooted soil. In particular, the results of direct shear tests with a large shear box $(300 \times 300 \times$ $100 \mathrm{~mm}$ ) and with a standard shear box are shown. The results confirm an increase in the soil shear strength, in terms of cohesion, when roots are present.

\section{INTRODUCTION}

The main function of levees is to protect urbanized areas from floods. Levees may differ in construction (earthworks, reinforced concrete, sheet piles, mixed solutions, etc.) and location (flooded banks, flood plain embankments, etc.).

Levees can fail in this intent due to one or more of the following Ultimate Limit States (ULS): overtopping, external erosion (scouring), internal erosion of the embankment body 
and/or the foundation soil, hydraulic heave (undrained uplift or static liquefaction), loss of global stability, excessive settlements and accidental actions (due to floating bodies). In Italy, several studies have been carried out concerning the failure of levees and possible countermeasures (see a few of many possible examples Di Prisco et al. 1995, Cosanti et al. 2014 and 2016, Bossi et al. 2018, Garuti et al. 2018, Squeglia et al. 2016).

The use of vegetation to stabilize slopes and reduce the risk of shallow landslides is an ecological and economic alternative to traditional civil engineering solutions. Plant roots play an important role in the protection of slopes against rainfall induced shallow landslides, in river bank stability, and in soil bioengineering structures (Stokes et al., 2009, 2014; Docker and Hubble, 2008, 2009; Hubble et al., 2013; Watson et al., 1999). More specifically, vegetation can contribute to the global stability of earth levees. Overall, the main beneficial effects of vegetation can be summarized as follows:

- interception: foliage and plants absorb rainfall energy;

- restraint: root systems physically bind or restrain soil particles while above-ground portions filter sediment out of runoff;

retardation: stems and foliage increase surface roughness and slow velocity of run off; infiltration: plants help to maintain soil porosity and permeability, thereby delaying onset of runoff;

Concerning the stabilizing effect of shallow mass:

roots reinforce the soil by transfer of shear strength in the soil due to the tensile resistance of the root;

soil moisture depletion: evapotranspiration and interception in the foliage can limit a

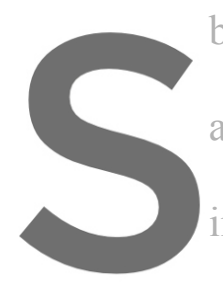

build-up of positive pere

buttressing and

abutments to counteract

surcharge: in

ncreased confining stress on

The mechanical
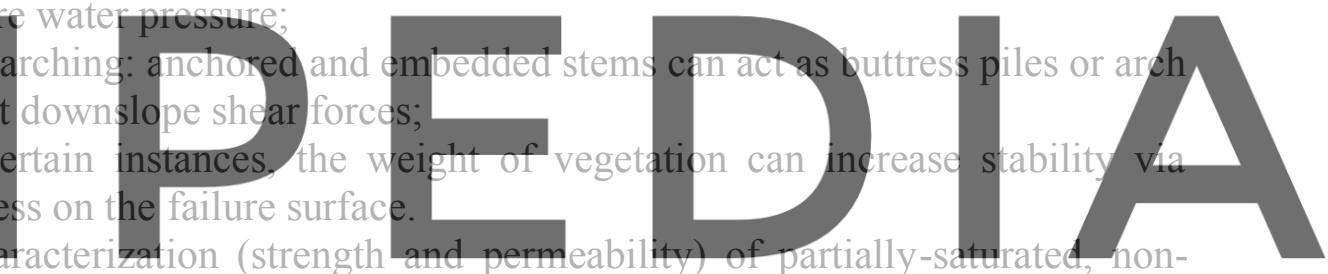

rooted soils is a key aspect in a safety evaluation of levees. Various approaches are available

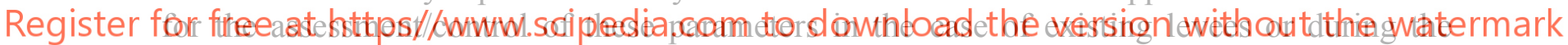

construction process of new ones. Tatsuoka (2015) demonstrated that the degree of compaction and related soil parameters (permeability and stiffness) depend on the degree of saturation during the earth-work construction. The dependence of the coefficient of permeability (measurements under saturated conditions) on the initial degree of saturation was confirmed by the experimental results of Scarcella et al (2018). They also demonstrated that the strength parameters depend on the degree of compaction. Lo Presti et al. (2018) proposed an expeditious approach to infer the degree of compaction of existing/new levees from the penetration resistance and water content, which is based on a measurement of tip resistance by means of a piezocone and an estimate of the water content.

Figure 1 shows the tip resistance obtained for various materials (A4 to A6 according to the AASHTO classification) vs. the degree of saturation. The results were obtained in the laboratory by using a mini - cone ( $8 \mathrm{~mm}$ in diameter). Tests were carried out on specimens reconstituted at $90 \%$ of the optimum density (modified Proctor). The specimens were reconstructed by static compaction in five layers and were consolidated in a mini - calibration chamber (320 mm diameter and $120 \mathrm{~mm}$ in height). Boundary (radial and vertical) stresses were applied. Lo Presti et al (2018) demonstrated that the tip resistance is not affected by the applied boundary stresses because suction is the dominant influential parameter besides the degree of compaction. The dependence of the tip resistance on the degree of saturation confirms such an interpretation. The CC series in Figure 1 also includes four pairs of data referring to in-situ 
determined tip resistance and degree of saturation. The in-situ degree of saturation and density were determined by retrieving cubic samples. The ' $A$ ' line represents the interpolation function of the above data. Figure 1 also reports the tip resistance and degree of saturation as determined by the investigation that was carried out in 2010 along the levees of the Serchio R. (Cosanti et al. 2014). Water content and degree of saturation were obtained from the analysis of undisturbed samples. Samples were retrieved from boreholes that were located at 1-2 $\mathrm{m}$ distance from the CPT vertical. It is possible to say that the experimental data from in situ tests above or near the A line are probably associated to a degree of compaction of about $90 \%$. Those remaining well below the A line are probably poorly compacted. Figure 1 confirms the poor degree of compaction of the Serchio R. embankments that were constructed in the XVIII century (Cosanti et al. 2014). Strength and permeability parameters for different degrees of compaction could be inferred from experimental works such as that of Scarcella et al. (2018). A specific A line, for any material under consideration, can be obtained by reconstituting one specimen in the calibration chamber. Indeed, mini-CPT can be repeated a number of times on the same sample therefore considering different water contents (Lo Presti et al. 2018). Obviously, this approach does not comply with the problem of extending the information obtained from one or more CPTs to a larger portion of the embankment.
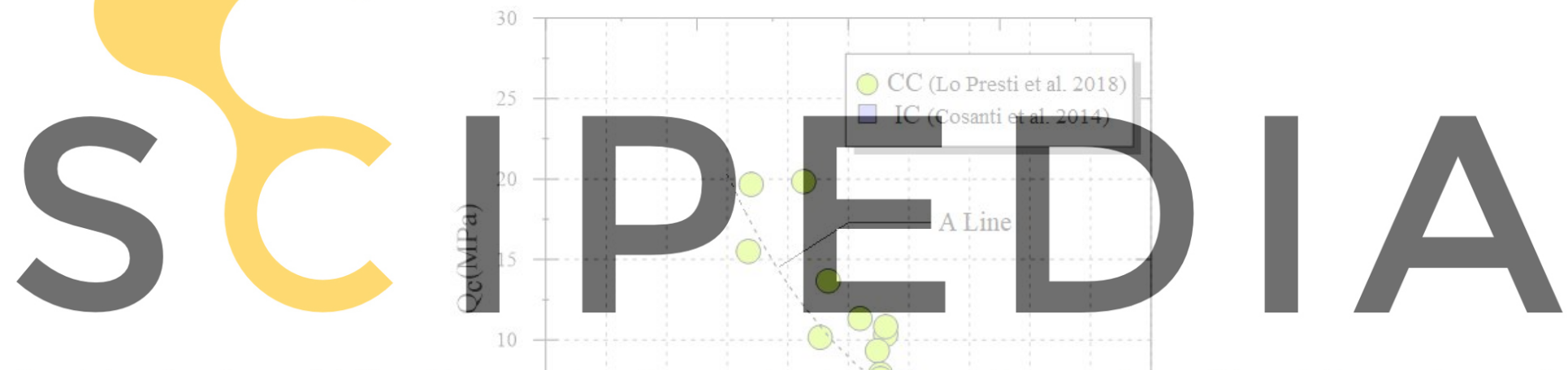

Register for free at https//www.scipedia.com to download the version without the watermark

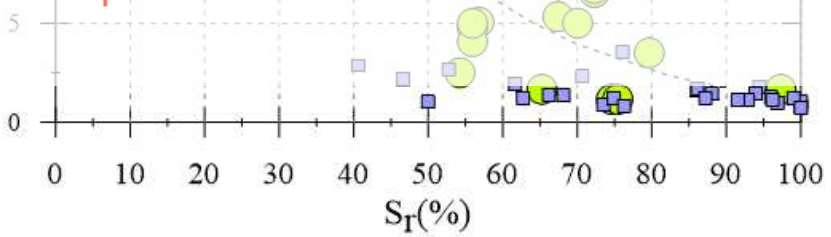

Figure 1: Cone tip resistance (qc) against the degree of saturation $(\mathrm{Sr})$.

If it is difficult to determine the strength and permeability parameters of partially saturated materials, the characterization of rooted and partially saturated soils is even more difficult. Moreover, few experimental data are available in the case of rooted soils and a rational completely satisfactory interpretation framework is still lacking.

It is believed that, mechanically, roots contribute to the stabilization/reinforcement of soil through an additional apparent cohesion. This apparent cohesion originates mainly from the root tensile strength as well as capillary forces in partially-saturated soils. In the last decade, research on root reinforcement has focused on several aspects: qualitative descriptions of mechanisms, quantitative estimates through experiments, development of theoretical models, and slope stability calculations. In all these cases, an experimental measure of root reinforcement is necessary to feed models and assess the mechanical role of vegetation on slope stability. These experiments require significant field and laboratory studies on roots, soils, 
and/or a combination of both. Such experimental investigations are time consuming, difficult to reproduce owing to the intrinsic variability of the materials, and often destructive. For example, tests used to estimate root tensile behaviour are affected by the intrinsic variability of roots and by a variety of methodological constraints (Capilleri et al., 2016, Capilleri et al., 2017). However, a large body of experimental work has been performed over the last 50 years, demonstrating the use of different techniques for measuring root reinforcement (e.g., root tensile strength in the field or in the laboratory and shear/tensile/ compressive strength of rooted soils). The evaluation of such reinforcement, in terms of root cohesion, can be obtained by means of direct shear tests (in situ or in laboratory). The authors set up a systematic experimental activity using a large direct shear box (Vannucci et al. 2019) with the purpose of considering the dual effect of suction and soil tensile strength. A series of direct shear tests were carried out. The preliminary results confirm the contribution made to soil shear strength by root reinforcement as already observed on a smaller scale.

\section{EXPERIMENTAL RESULTS}

The interaction between plants and soil has been studied in different research areas. From an engineering point of view, plants can improve the mechanical characteristics of the soil. They play an active role both on the surface where they protect and hold soil particles, and also at deeper layers, reducing pore pressure and increasing soil shear strength. Using vegetation is particularly appropriate where soil conservation measures are needed. (Capilleri et al., 2019). To this end, the preliminary results are reported of an experimental laboratory investigation on rooted soil samples, carried out through direct shear tests using both a large and the standard

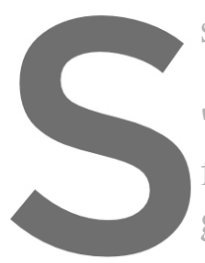
shear box.

The experiment concerned thr "Podere Ragnaino", locat few tens of meters from growth was not affected grass family (Zoysia). It is characterized by a dense, robust root system and does not require much maintenance, as it is also resistant to low temperatures (Figure 3).

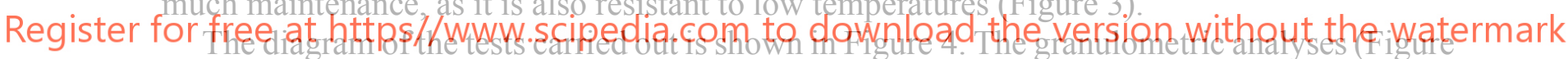
5) made it possible to classify in the soils constituting the three samples as sandy silts with low clay content, with an average water content of $22 \%$ at the time of sampling. 

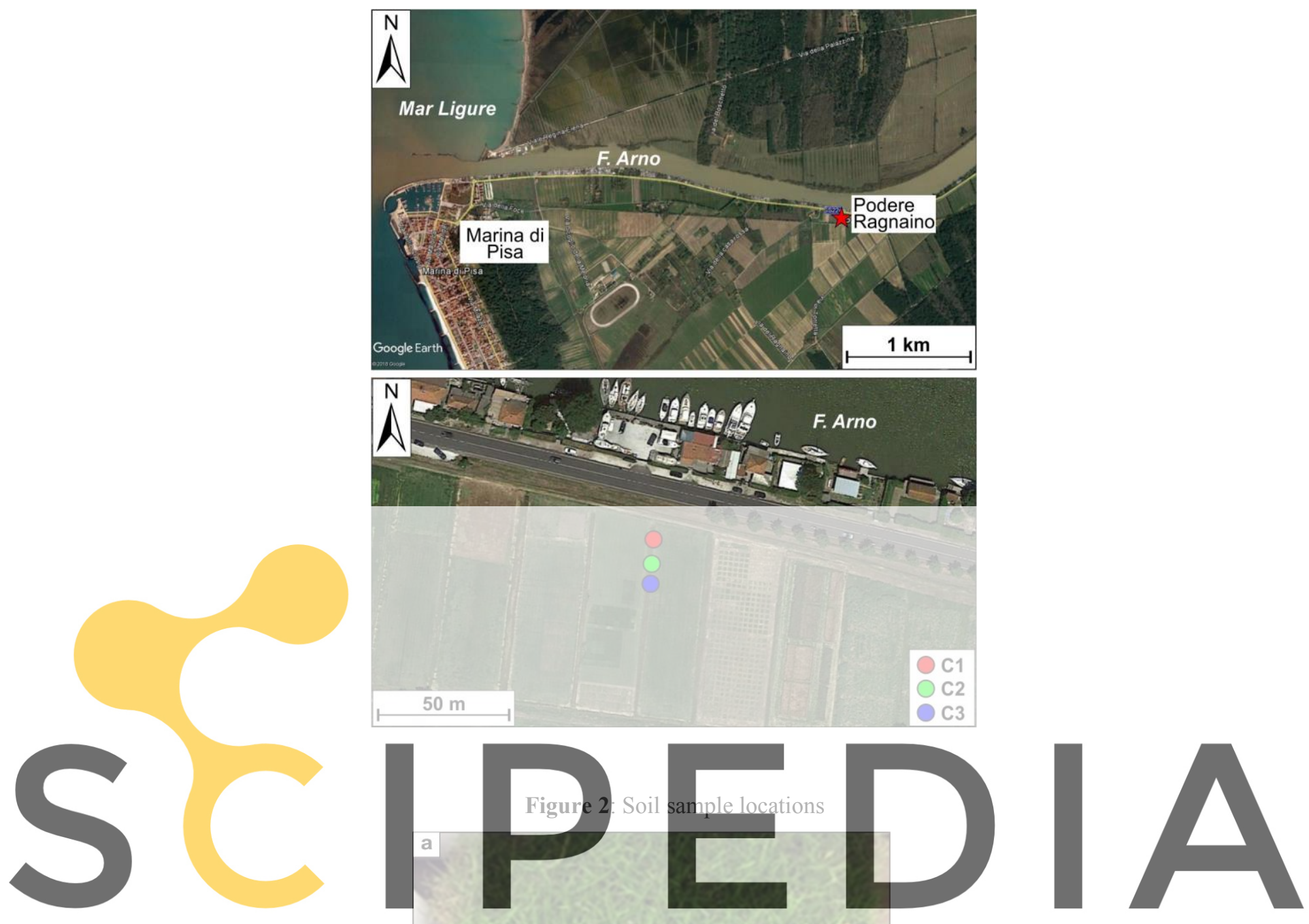

Register for free at https//www.scipedia.com to download the version without the watermark

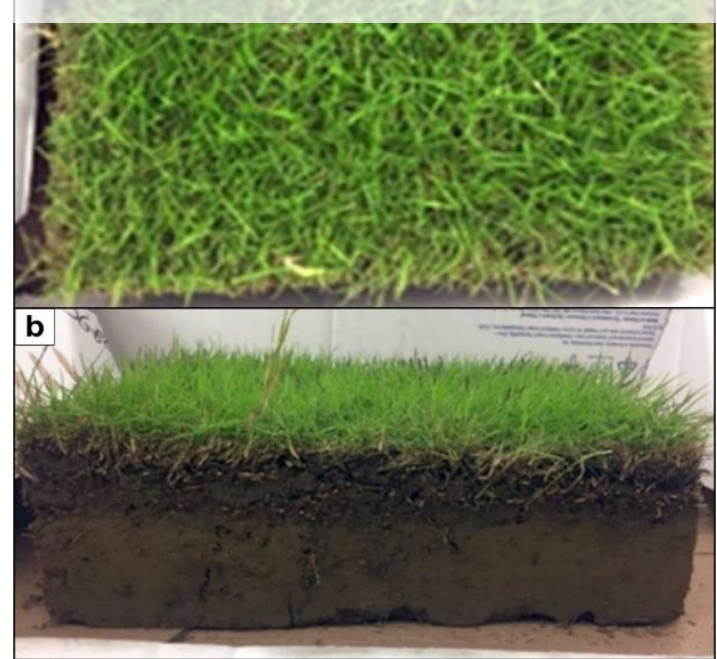

Figure 3:View of rooted soil samples: a) from above; b) section 


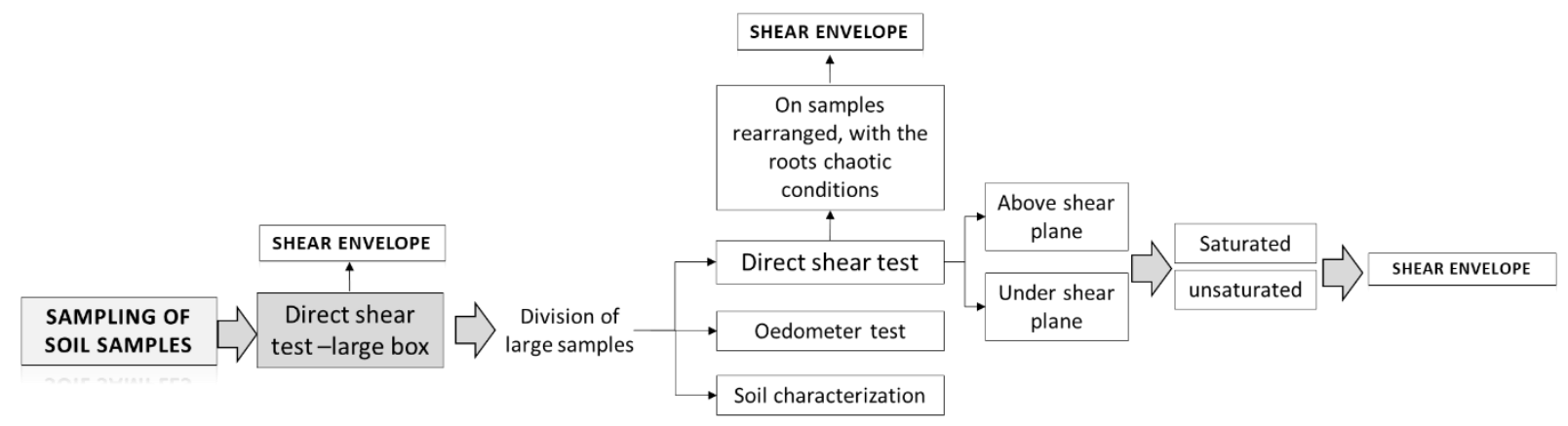

Figure 4: Scheme of tests



Register for free at https//www.scipedia.com to download the version withbiatmethem (watermark

Figure 5: Grain size distribution

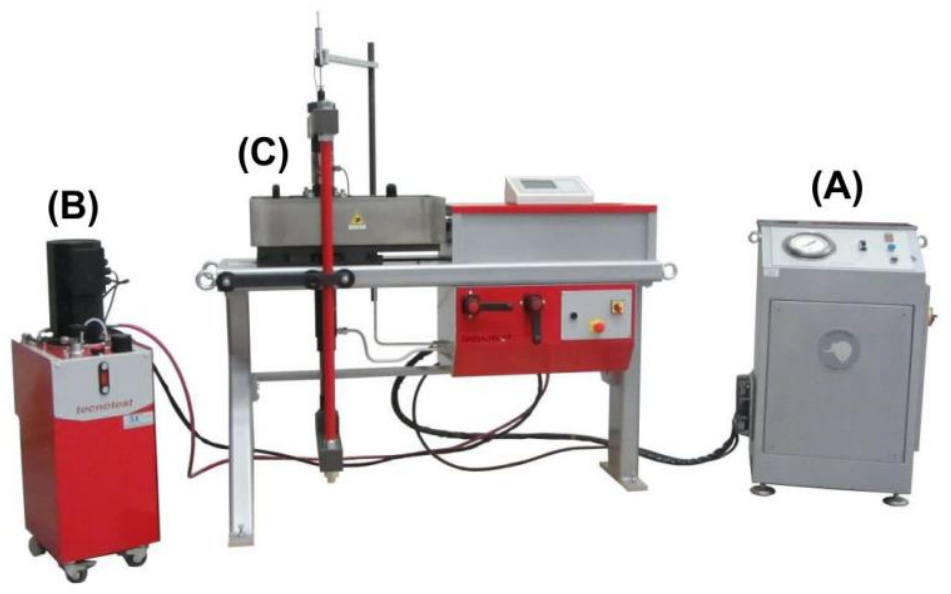

Figure 6: Direct large shear apparatus: A) Vertical load unit, B) Horizontal displacement unit, C) shear box 
Direct shear tests were carried out on the three samples (C1, C2, C3 - Figure 3) with the large shear box. The prototype large shear apparatus (Figure 6) (Tecnotest model ZZ700/L97), supplied to the University of Pisa, allows shear resistance to be determined on large-size samples $(300 \times 300 \times 100 \mathrm{~mm})$ (Vannucci et al., 2019).

After testing with the large shear apparatus, each sample $(\mathrm{C} 1, \mathrm{C} 2, \mathrm{C} 3)$ was then divided into four pieces and each piece was then subdivided into two parts with respect to the shear surface. Each piece of soil presented an upper part of the shear surface with a greater number of in roots and therefore larger water content and a lower part of the shear surface whit less in roots and therefore a smaller water content. A total of 24 small specimens were obtained (Figure 7), of which 12 came from clods under the shear surface (bottom) while the same number were obtained from clods above the shear surface (top).

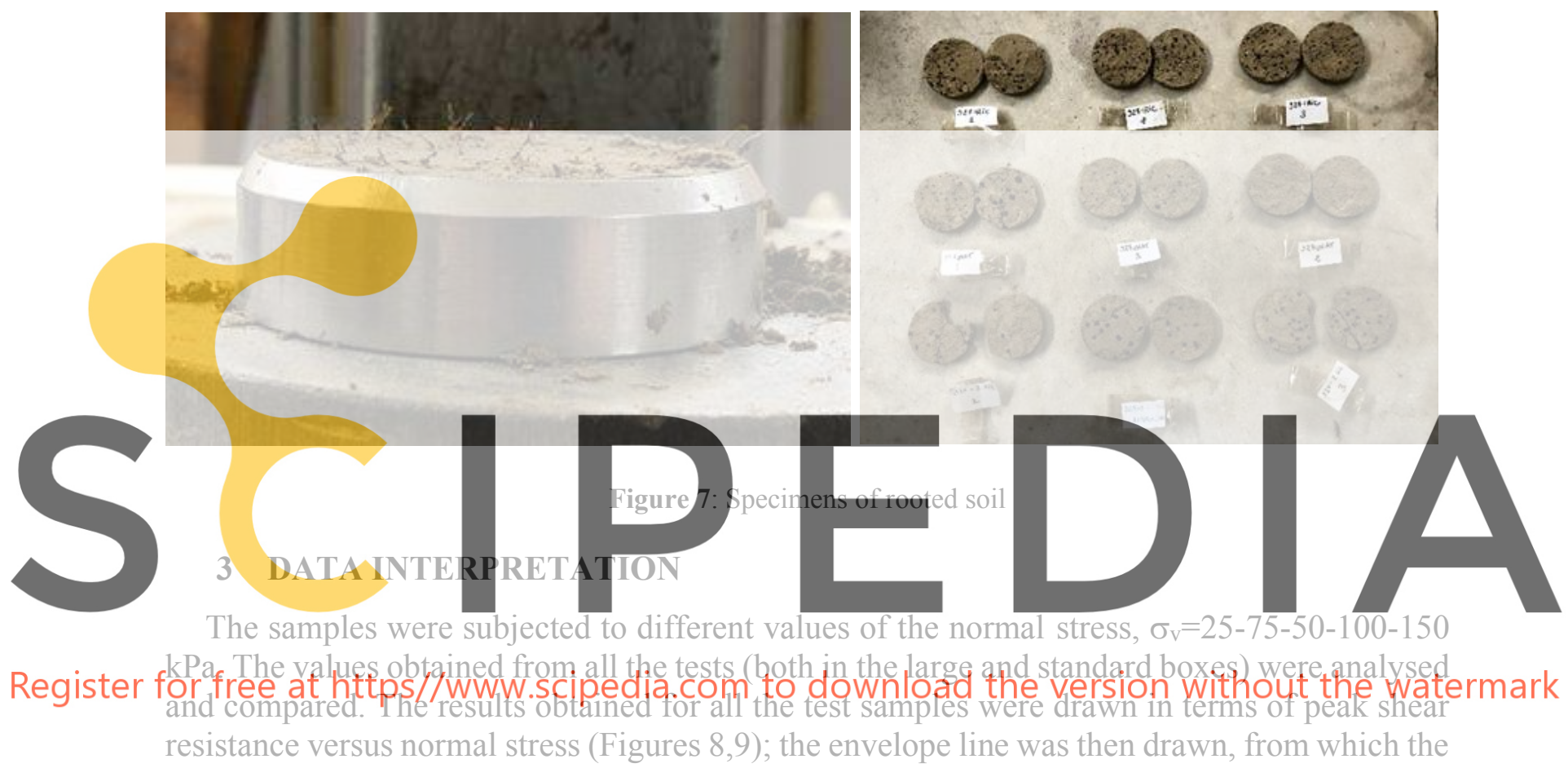

resistance parameters $c^{\prime}$ and $\varphi^{\prime}$ were determined.

In particular, the results in terms of $\tau-\sigma$ were grouped into saturated samples (Figure 8 ) and unsaturated samples (Figure 9). Saturated samples were characterized by an average degree of saturation of $95 \%$, while unsaturated samples had an average degree of $78 \%$.From the shear envelopes shown in Figures 10 it is possible to observe that the value of the friction angle remains unchanged while there is an increase in the cohesion value from saturated and unsaturated samples. This contribution, which is reflected in an increase in cohesion, has been quantified at a value of $16 \mathrm{kPa}$.

The comparison highlights the regulatory function of the roots that influence saturated permeability and also the value of suction that increases resistance. 


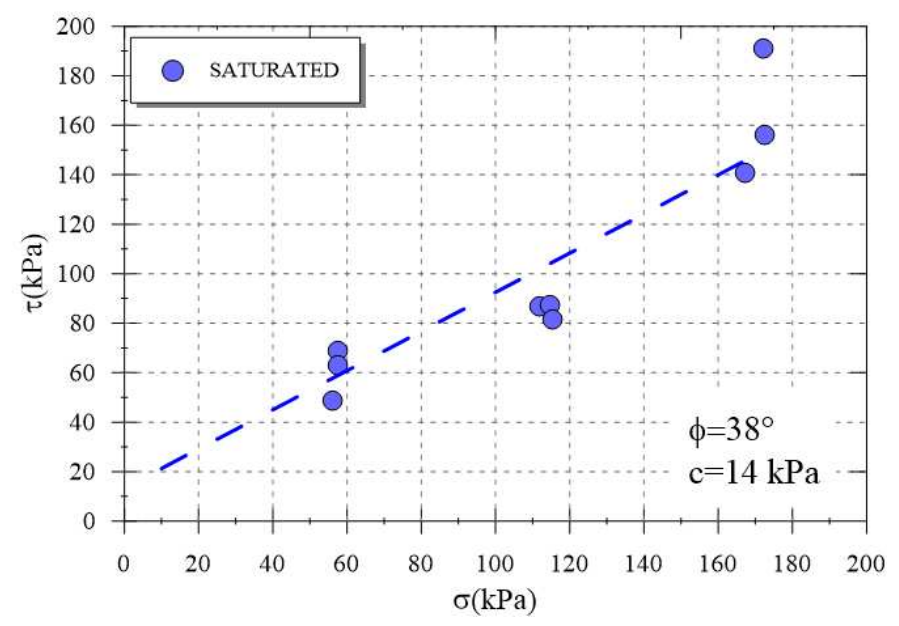

Figure 8: Shear envelopes of saturated rooted samples obtained by shear tests
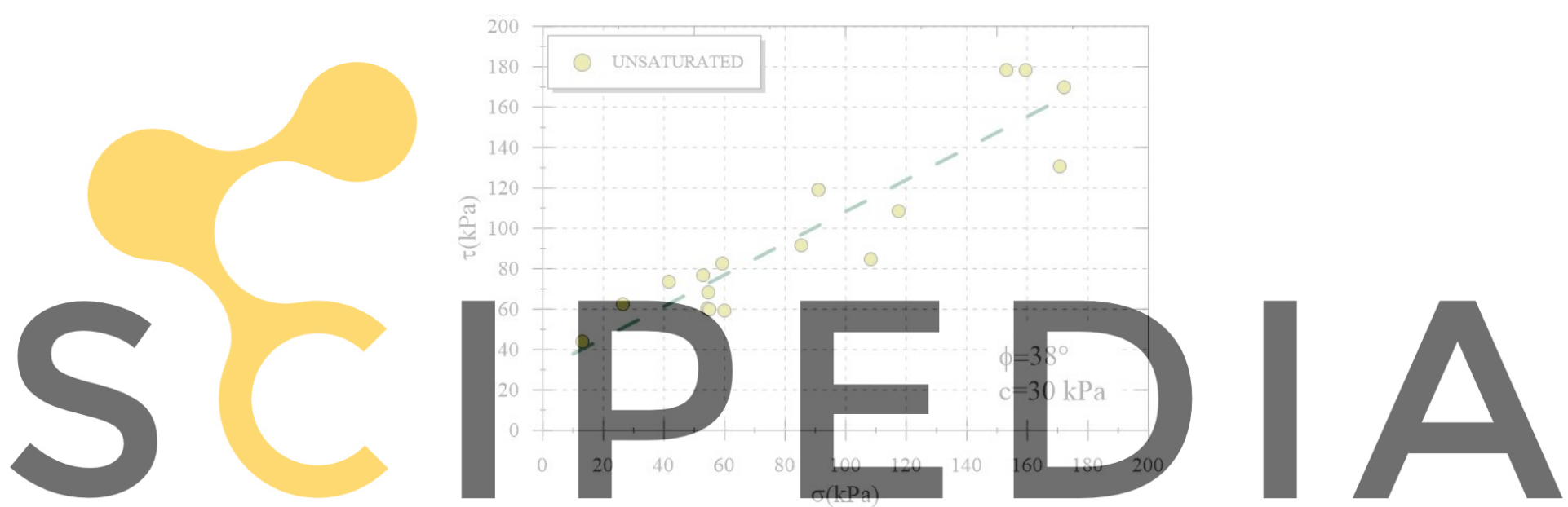

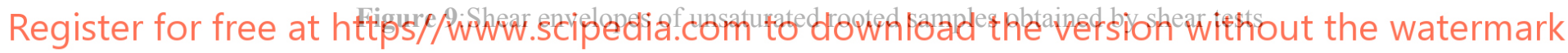

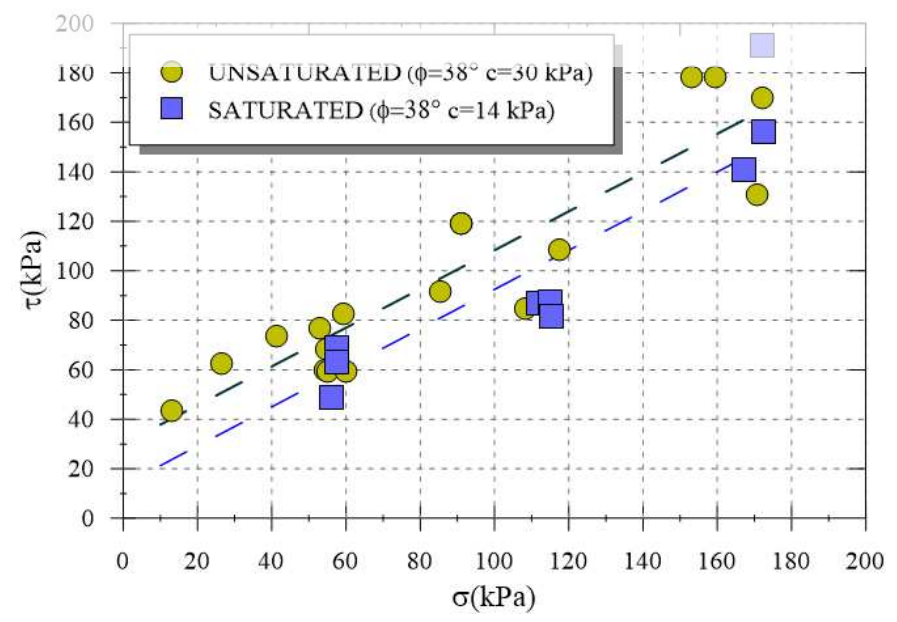

Figure 10: Comparison of shear envelopes of saturated and unsaturated samples 


\section{CONCLUSIONS}

When soil is reinforced by a rooted grassy surface (a graminacea was considered in this study) then the shear resistance of the soil increases due to the mechanical effects of the roots. Most of the earlier studies focused on this effect in saturated soil conditions while this experiment also included partially-saturated soils .

The soil adjacent to the roots is generally partially saturated and this leads to alterations in the mechanisms of soil-root interaction and to greater complexity and uncertainty in the assessment of shear resistance of the soil-root system. In this work, the increase in shear resistance was also analysed considering the effect of partial saturation, in which suction plays a significant role.

The experimental tests for verifying the behaviour of rooted soil samples, using two types of shear apparatus, are still in the preliminary phase. In particular, the number of tests with a large shear box must be increased in order to provide further results to compare with those obtained with the standard box. Thus it will be possible to verify the reliability of the appliance that allows larger portions of soil with the presence of roots to be analysed.

The results obtained indicate that the shear strength behaviour of the soil-root system is significantly regulated by the degree of suction.

\section{REFERENCES}

[1] Bossi, G., Bersan, S., Cola, S., Schenato, L., De Polo, F., Menegazzo, C., and Simonini, P. (2018). Multidisciplinary Analysis and Modelling of a River Embankment Affected by Piping. In European Working Group on Internal Erosion (pp. 234-244). Springer, Cham. Capilleri P.P., Motta E., and Raciti E. (2016). Experimental study on native plant root
tensile strength for slope stabilization. VI Italian Conference of Rescarchers in
Geotechnical Engi-neering -Geotechnical Engineering In Multidisciplinary Research:
From Microscale To Re-gional Scale. CNRIG Bologna, 2016 22-23 Settembre.
Capilleri, P.P., Motta, E., Raciti, E., and Todaro, M. (2017). Evaluation of root tensile strength of some Mediterranean plant species for slope stabilization. Rivista Italiana di

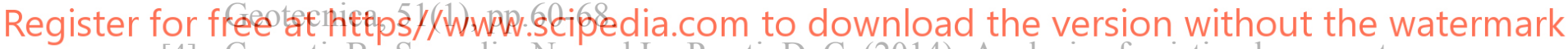

[4] Cosanti, B., Squeglia, N., and Lo Presti, D. C. (2014). Analysis of existing levee systems: the Serchio river case. Rivista Italiana di Geotecnica 48, 49-67.

[5] Cosanti, B., Squeglia, N., and Lo Presti, D. (2016) A case history on levee external erosion. Rivi-sta Italiana di Geotecnica 3/2016: 37-44.

[6] Di Prisco, C., Matiotti, R., and Nova, R. (1995). Theoretical investigation of the undrained stabil-ity of shallow submerged slopes. Géotechnique, 45(3), 479-496.

[7] Docker, B., and Hubble, T., (2008). Quantifying root-reinforcement of river bank soils by four Australian tree species. Geomorphology 100 (3-4), 401-418.

[8] Docker, B., and Hubble, T., (2009). Modelling the distribution of enhanced soil shear strength be-neath riparian trees of South-Eastern Australia. Ecol. Eng. 35 (5), 921-934.

[9] Garuti, D., Jommi, C., and Rijkers, R. (2018). The Role of the Hydraulic Resistance of the River Bed and the Time Dependent Response of the Foundation Layers in the Assessment of Water Defences for Macrostability and Piping. In European Working Group on Internal Erosion (pp. 258-271). Springer, Cham.

[10] Hubble, T. C. T., Airey, D. W., Sealey, H. K., De Carli, E. V., and Clarke, S. L. (2013). A little cohesion goes a long way: Estimating appropriate values of additional root cohesion for evalu-ating slope stability in the Eastern Australian highlands. Ecological engineering, 61, 621-632.

[11] Lo Presti, D.; Giusti, I.; Cosanti, B.; Squeglia, N.; and Pagani, E. (2016) Interpretation of CPTu in" unusual" soils. Rivista Italiana di Geotecnica, 50(4), 23-42. 
[12] Lo Presti D., Squeglia, N., and Cosanti, B. (2018) Evaluating Degree Of Compaction Of Levees Using Cone Penetration Testing Journal of GeoEngineering, Vol. 13, No. 3, pp. 1-14, Septem-ber 2018 http://dx.doi.org/10.6310/jog.201809_13(3).1

[13] Lo Presti, D., Stacul, S., Meisina, C., Bordoni, M., and Bittelli, M. (2018b). Preliminary Valida-tion of a Novel Method for the Assessment of Effective Stress State in Partially Saturated Soils by Cone Penetration Tests. Geosciences, 8(1), 30.

[14] Lo Presti, D. L., Stacul, S., Capilleri, P. P., \& Squeglia, N. (2020). Assessment of Factors Contributing to Levees Stability. In National Conference of the Researchers of Geotechnical Engineering (Vol. 40- pp. 111-120). Springer, Cham. ID SCOPUS: s2.085068156763. ISSN: 23662557. DOI:10.1007/978-3-030-21359-6_12.

[15] Scarcella, G. E., Giusti, I., Giusti, S., Lo Presti, D., and Squeglia, N. (2018). Strength and perme-ability parameters of compacted partially saturated silty and sandy soils. Rivista Italiana di Geotecnica, 52(1), 59-70.

[16] Squeglia, N., Cosanti, B., and Lo Presti, D. (2016). Importance of full scale tests for the design of levees. Rivista Italiana di Geotecnica, 50(4), 43-54.

[17] Stokes, A., Atger, C., Bengough, A. G., Fourcaud, T., and Sidle, R. C. (2009). Desirable plant root traits for protecting natural and engineered slopes against landslides. Plant and soil, 324(1-2), 1-30.

[18] Stokes, A., Douglas, G.B., Fourcaud, T., Giadrossich, F., Gillies, C., Hubble, T., Kim, J.H., Loades, K.W., Mao, Z., Mcivor, I.R., Mickovski, S.B., Mitchell, S., Osman, N., Phillips, C., Poesen, J., Polster, D., Preti, F., Raymond, P., Rey, F., Schwarz, M., and Walker, L.R., (2014). Ecological mitigation of hillslope instability: ten key issues facing

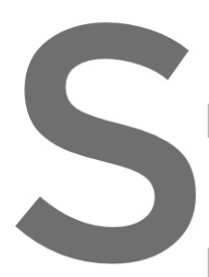
researchers and 1 014.

[19] Tatsuoka, F. (2015) soil con-trolled by on Defor-mation C
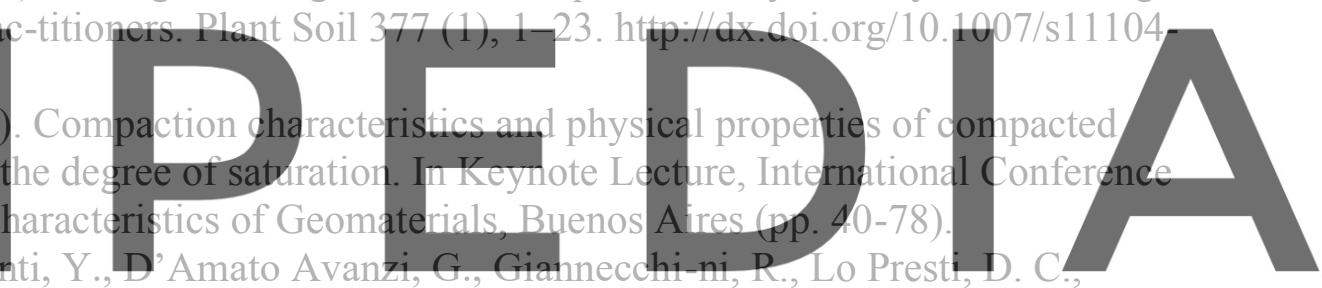

Capilleri, P. P. F. (2019). Strength parameters of debris by using a large shear box appa-

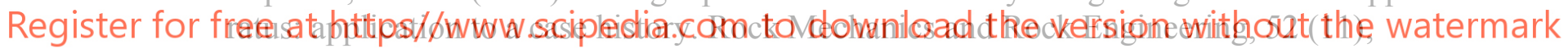
4421-4437.

[21] Watson, A., Phillips, C., and Marden, M., (1999). Root strength, growth, and rates of decay: root reinforcement changes of two tree species and their contribution to slope stability. Plant Soil 217 (1-2), 39-47. 